\title{
Erratum to: \\ Structural Design of the Rainwater \\ Harvesting System
}

\author{
Qiang Zhu
}

\section{Erratum to:}

\section{Chapter 3 in: Q. Zhu et al. (eds.), Rainwater Harvesting for Agriculture and Water Supply, DOI 10.1007/978-981-287-964-6_3}

The original version of this chapter unfortunately contained a mistake. The Figure 3.39 was initially wrong, the correct figure should be the one as given below.

The updated original online version for this chapter can be found at DOI: 10.1007/978-981-287-964-6_3

Q. Zhu ( $ه)$

Gansu Research Institute for Water Conservancy, Lanzhou, China e-mail: zhuq70@163.com 


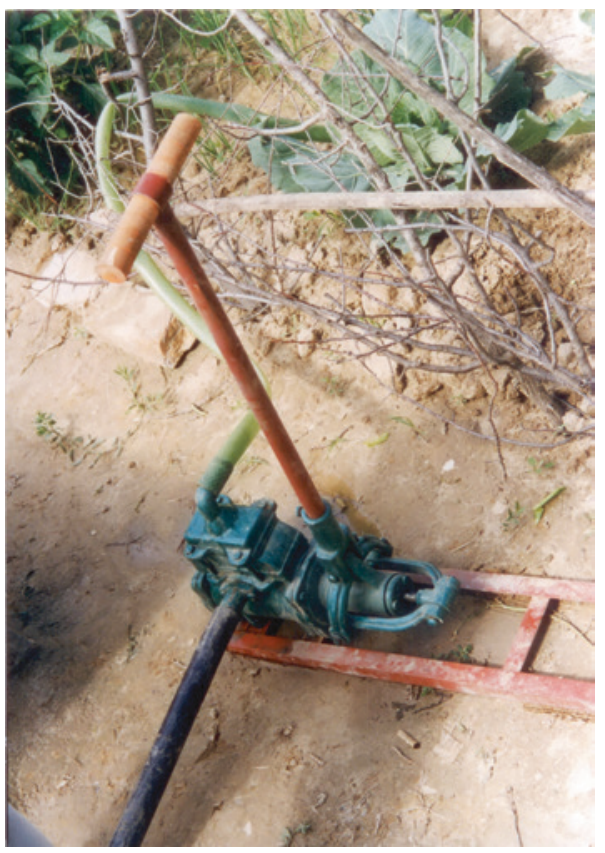

Fig. 3.39 Hand pump for irrigation 